\title{
A simbologia presente nos estilos de Karate-Dō
}

CDD. 20.ed. 796.84

http://dx.doi.org/10.1590/1807-55092015000300395
Brandel José Pacheco LOPES FILHO*/** Alberto de Oliveira MONTEIRO**

\section{Resumo}

0 objetivo deste estudo é interpretar os diferentes significados existentes nos emblemas/símbolos de estilos e escolas de Karate-Dō, analisando seus elementos internos e sua importância dentro dessa prática. Para sua realização, foram realizadas três etapas distintas: 1) catalogação e investigação dos estilos e escolas de Karate-Dō com maior representatividade histórica, cultural e política; 2) identificação dos símbolos utilizados por cada um desses estilos e escolas; e 3) análise de cada um desses símbolos. Essa análise torna-se importante para uma compreensão mais profunda dos diferentes significados envolvidos na prática do Karate-Dō, pois, apesar de seguirem um conjunto de valores comum a todos os Budō, as escolas possuem sua própria visão de mundo, utilizando seus símbolos para reforçar ou externar tais conceitos. A maior parte dos símbolos analisados demonstra um aprofundamento cultural em seus grafismos, sendo reconhecidos alguns elementos até de aspecto espiritual ou religioso. Esse simbolismo, em si, mostra um aspecto relevante para a compreensão do próprio fenômeno multicultural nomeado Karate-Dō.

PalavRas-Chave: Karate; Artes marciais; Esporte; Cultura japonesa; História.

\section{Introdução}

O mundo é permeado por símbolos das mais variadas formas: podem ser mais claros e objetivos, como brasóes familiares e bandeiras, ou podem se apresentar de forma mais sutil, como ocorre no caso de mitos e lendas culturais. Independente de sua apresentação, tais símbolos representam aspectos da natureza humana, suas crenças e emoçóes, sejam elas positivas ou negativas ${ }^{1}$.

Os desportos e as práticas corporais, de maneira geral, também são permeados por diversos símbolos e elementos. Os Jogos Olímpicos, por exemplo, são representados pela bandeira dos Cinco Anéis, além de possuir um logotipo específico a cada edição, que representa o país onde ocorre o evento naquele momento. As próprias federaçóes esportivas e outras instituiçôes de caráter similar adotam uma marca que as represente, muitas vezes elaboradas por profissionais de Design ou Publicidade, para que sejam reconhecidas, obtenham representatividade e causem identificaçấo.

Um processo muito semelhante ocorre com os diferentes estilos, ou mais precisamente, com as diferentes escolas de Karate-Dō. Â exceção do uso da escrita kanj $i^{2}$ para nomeá-lo, não há um símbolo universal para essa prática corporal, apenas os símbolos adotados por instituiçóes ou estilos. No entanto, cada um desses elementos visuais parece possuir significados diversos.

Com base nessas informaçóes, o objetivo deste estudo é interpretar os diferentes significados existentes nos emblemas/símbolos de estilos e escolas de Karate-Dō, analisando seus elementos internos e sua importância dentro dessa prática. Esse trabalho se justifica por aprofundar-se em um tema pouco explorado em publicaçôes de artes marciais: a simbologia presente nos diferentes estilos de Karate- $D \bar{o}$. Tais aspectos são importantes de serem investigados, pois remetem à própria cultura envolvida na criação e desenvolvimento das práticas corporais nomeadas como artes marciais ${ }^{2}$.

O texto apresenta diversas palavras de origem japonesa, essenciais para o estudo aqui proposto. Portanto, adotou-se a romanização padronizada pelo sistema $\mathrm{He}$ $p_{b u r n}$ (ヘボン) para a transcrição fonética do idioma japonês, seguindo as normativas internacionais propostas por Ross ${ }^{3}$. Isso se faz necessário para que a tradução e interpretaçáo dos termos estejam em conformidade com as normas de adaptaçáo estrangeira. Muitas das palavras não estarão de acordo com a acentuação e regras ortográficas da Língua Portuguesa, e sim, representando o que seria uma pronúncia da Língua Japonesa. 


\section{Método}

Para a realização desse estudo, foram realizadas três etapas distintas: 1) catalogação e investigação dos estilos e escolas de Karate-Dō com maior representatividade histórica, cultural e política, com base na literatura consultada; 2) identificaçáo dos símbolos utilizados por cada um desses estilos e escolas; e 3) análise, com base na literatura, de cada um desses símbolos. De tal forma, foi possível fazer um levantamento e uma distinção entre os diversos estilos, elementos e símbolos que permeiam a vasta cultura do Karate-Dō.

Na etapa de catalogação, buscou-se conhecimento do maior número possível de estilos existentes em fontes como livros, artigos e páginas na "internet" de instituiçôes e Federaçóes ligadas ao Karate-Dō. Destacamos aqui as páginas da World Karate Federation (WKF), da World Union of Karate-Do Federations (WUKF) e da World United Karate Organization (WUKO), as quais possuem diversos estilos filiados. Com base nesse material foi desenvolvido um desenho procedimental que forneceu o referencial teórico para o trabalho e realizada a seleção dos estilos a serem investigados. As informaçóes coletadas foram submetidas à análise documental que, segundo BARDIN ${ }^{4}$, consiste em realizar operaçóes de desmembramento do texto em unidades de significado, buscando desvendar seus diferentes sentidos.

\section{Resultados e discussão}

\section{Cenário histórico e político-institucional}

A origem do Karate-Dō - Caminho das Mãos Vazias - se constitui em um grande processo multicultural, confundindo-se, muitas vezes, com lendas e ditos populares ${ }^{7}$. Como exemplo, algumas dessas estórias nos contam que as técnicas teriam sido inspiradas em movimentos de animais (uma característica do Wushu chinês); outras defendem que o Karate-Dō teria surgido no território geográfico japonês, como prática originada nos antigos Jutsu (técnicas guerreiras tradicionais do Japão), o que não é corroborado pelas fontes históricas ${ }^{8-9}$.

As origens do Karate-Dō remontam à Okinawa do século XIV, na época a principal ilha do Reino independente de Ryūkyü, vassalo da China, que mais tarde foi incorporado ao Japão Continental. Devido a essas características, é assumido que o intercâmbio cultural ocorrido entre estas três localidades (Okinawa, China e Japão) foi fundamental para o
Identificados os estilos e escolas mais relevantes para o estudo, foi realizada a segunda etapa, que consistia no levantamento dos símbolos que cada um utiliza para sua identificação, caso o façam. Para tanto, buscamos as publicaçóes pertinentes a cada estilo, seja na forma de livros ou nas páginas de "internet" oficiais das instituições, também submetidas à análise documental ${ }^{4}$. Não só os símbolos isolados foram reunidos, mas fotografias em que praticantes de Karate-Dō aparecem os utilizando, seja em suas vestes ou em decoraçáo de eventos.

A última etapa consistiu na análise dos símbolos e fotografias encontrados e selecionados, que resultaram em 167 imagens. Para sua análise foi utilizada a Metodologia Visual de Gillian Rose ${ }^{5}$, que aponta três aspectos para sua avaliação: 1) os locais onde foi produzida a imagem; 2) a imagem em si; 3 ) onde esta imagem é vista e, por consequência, por quem é vista. Com base nesse método, surgem diversas perguntas: Quando foi produzida a imagem? Quem a produziu? Qual sua finalidade? Qual a função das cores escolhidas? Quais conteúdos basearam sua produção? Ela faz parte de uma série? Tal etapa é fundamental, pois confiamos que "as imagens revelam, a seu modo, o interior e o exterior dos sujeitos"6 (p.34).

desenvolvimento desta arte marcial, culminando na prática que hoje conhecemos ${ }^{9}$. Assim sendo, não seria possível aprofundar-se nos conteúdos estudados aqui sem uma breve revisão de tal processo.

Como ocorreu nos inúmeros feudos na história humana, os camponeses de Okinawa (Heiminc) se encontravam em uma posição social desprivilegiada, sendo afligidos pela cobrança de tributos exigidos pela nobreza ${ }^{10}$. $\mathrm{O}$ não pagamento dessas dívidas culminava em atos de agressão por parte dos Peichin ${ }^{\mathrm{d}}$, a classe militar guerreira de Okinawa responsável pela cobrança dos impostos ${ }^{11}$. Devido a esse contexto, os Heimin criaram formas de combater a casta guerreira, surgindo, assim, o que veio a ser denominado como $T e$ (ou $T i$, na pronúncia nativa de Okinawa), uma técnica de combate mais rudimentar ${ }^{11-12}$. Em um texto histórico ${ }^{9}$, fornecido pela Prefeitura de Okinawa, é afirmado que o $T e$ "existia desde tempos antigos em Okinawa", anteriores à vassalagem chinesa. 
Posteriormente, o $T e$ foi sendo apropriado pelos próprios Peichin, que a mesclaram com práticas de luta provenientes da China a partir do século XIV d.C., graças a visitas diplomáticas chinesas, as quais culminavam em trocas culturais. Isso deu origem ao Tōdee (pronúncia de Okinawa) ou Karate (pronúncia japonesa), que significava literalmente "Mãos Chinesas" ${ }^{\prime 13-14}$. Outro fato que influenciou seu desenvolvimento, neste período, foi a vinda do Clã Shimazu ${ }^{\mathrm{f}}$ de Satsuma, em 1609 d.C., samurai provenientes de Kyūshū (Japão) $)^{7,9}$. Neste período, as províncias de Okinawa mais importantes na história do Karate-Dō foram Naha, Shuri e Tomaris ${ }^{\mathrm{s}}$, que deram origens aos estilos da época: Naha-Te ${ }^{\mathrm{h}}$, Shuri-Te e Tomari-Te, respectivamente. ${ }^{9}$ O Naha-Te é um estilo que visa trabalhar o corpo em conjunto com a mente e o espírito, com técnicas de movimentos circulares que, não apenas reforçariam o corpo, mas atingiriam aspectos ditos energéticos (ou espirituais) do ser humano, tal qual o fazem certas práticas chinesas. O Shuri-Te já aparenta ter sido uma linha mais corporal, com movimentos lineares e diretos, enquanto o Tomari-Teé um estilo que optou por mesclar ambos os anteriores ${ }^{15}$.

Em meados de 1920, Gichin Funakoshi, nativo de Okinawa e praticante de Tóde/Karate, após diversas apresentaçóes e visitas diplomáticas, introduziu a disciplina no Japão continental, alterando seu nome, seus objetivos e seu método de ensino. A arte conhecido como Tóde/Karate (唐手 - "Máos Chinesas"), teve sua forma de escrita alterada e passou a ser chamado de Karate (空手 - "Mãos Vazias") e, posteriormente, de Karate-Dō (空手道 - “Caminhos das Mãos Vazias"), ingressando no Japão, definitivamente, como um Budo ${ }^{-k, 16}$.

Apesar de não surgir dentro do território japonês, o Karate- $D \bar{o}$ veio a se desenvolver, de forma fundamental, também através das trocas culturais com imigrantes japoneses que se estabeleciam em Okinawa ${ }^{7,9}$. Aliado a diversos outros esforços, tal característica pode ter facilitado o registro da arte como um Budo. No entanto, isso fez com que, em certas ocasióes, o Karate-Dō não fosse reconhecido como uma verdadeira arte marcial japonesa ${ }^{7,16-17}$.

Com a fundação da Dai Nippon Butoku-kail, toda arte marcial deveria ser registrada na instituição e seguir suas normas para tornar-se um Budo, desde que fosse uma antiga disciplina marcial japonesa. Náo era esse o caso do Karate- $D \bar{o}$, arte trazida de uma ilha com fortes influências chinesas. Um dos aspectos desse novo período é que as antigas técnicas de luta, que utilizavam o termo Jutsu em seu nome, deveriam passar a utilizar o sufixo Dō em substituição (Kenjutsu passa a ser Kendō, por exemplo) $)^{8-9,16}$. O Karate-Dō nem mesmo consta na lista da instituição referente a essas antigas técnicas guerreiras; aparece diretamente com sua nomenclatura atual ${ }^{18}$. Conforme observado, a situação do Karate-Dō enquanto Budō, à época de seu registro oficial, desenrolou-se de forma um tanto diferente das demais práticas. Isso, aliado a toda sua história prévia, reforça a característica multicultural da arte e coloca-se contrário a certos entendimentos, os quais posicionam o Karate-Dō como uma "genuína construção cultural japonesa”, conforme já salientado pelo antropólogo Kevin $\operatorname{Tan}^{8}$ (p.169).

As escolas de Okinawa (Naha-Te, Tomari-Te e Shuri-Te) foram exportadas para o Japão e, posteriormente, para o mundo, originando ainda mais linhagens distintas ${ }^{16}$. Com o passar do tempo, essa arte foi desportivizada e institucionalizada em organizaçóes regionais, nacionais e internacionais ${ }^{19}$. Atualmente, as organizaçóes internacionais de maior representatividade são a World Karate Federation (WKF), a World Union of Karate-Do Federations (WUKF) e a World United Karate Organization (WUKO), as quais possuem diversas escolas e organizaçóes filiadas.

A WKF é o órgão reconhecido pelo Comitê Olímpico Internacional (COI) como o organizador do Karate-Dō em nível mundial, sendo que apenas os filiados a ela, seja diretamente ou por intermédio de outras federaçóes, podem participar das competiçóes oficiais ${ }^{20}$. Esta é, talvez, a organização de Karate-Dō de maior importância política no mundo desportivo atual. Os estilos admitidos pela WKF em suas competições são Gōjū-ryū, Shitō-ryū, Shōtōkanryū e Wadō-ryū, os quais são reconhecidos no Japão como os "Quatro Grandes Estilos" $\mathrm{m}, 15$.

A WUKF, fundada em 1970, é, talvez, a segunda maior entidade de nível mundial a representar o Karate-Dō. Além dos mesmos quatro estilos da WKF, ela reconhece outros quatro: Budōkan, Shörin-ryū, Kyokushin e Uechi-ry $\bar{u}^{21}$. Já a WUKO é a mais recente das organizaçôes, sendo oficialmente batizada em 1990. É a única das três que não limita o número de estilos filiados, mas também não possui o reconhecimento do COI em suas competiçóes ${ }^{22}$. Observando-se as normas estabelecidas pelas organizaçóes locais de cada país (confederações e federaçôes), de forma geral, qualquer membro pode se filiar às três instituiçôes citadas.

É importante salientar que o reconhecimento oficial pelo Comitê Olímpico trata apenas da organização e participação de atletas em eventos esportivos, bem como apoio e obtençáo de fundos para esse fim. De maneira alguma, esse reconhecimento se estende 
à prática da arte em geral ou barra os eventos das outras organizações, os quais possuem uma importância, no mínimo, igual aos realizados pela WKF.

\section{Os estilos de Karate-Dō}

Atualmente existem mais de 60 estilos de Karate-Dō no mundo inteiro ${ }^{23}$. Muitos deles surgiram em Okinawa, enquanto outros foram criados em solo japonês, após a inserção dessa arte no país. Ainda existiriam estilos ocidentais, pois após a Segunda Guerra Mundial houve uma ocupação do território japonês pelos Estados Unidos da América, o que colaborou para que o Karate-Dō fosse difundido pelo mundo. Muitos militares americanos aprenderam a arte e, ao retornar para sua pátria, abriram escolas e estilos próprios, a maioria deles não sendo reconhecidos no Japão ${ }^{23-24}$.

A escolha de um estilo de Karate-Dō se reflete em toda a prática do aluno, pois cada um possui suas próprias normas, características técnicas e filosóficas, que complementam os valores universais dessa arte. Delinear todos os estilos presentes no cenário atual seria uma tarefa quase impossível de se realizar e longe do foco deste trabalho. Sendo assim, limitamos os estilos investigados utilizando os seguintes critérios de inclusão: a) fazer parte de pelos menos três organizaçóes interestilos de Karate-Dō a nível, no mínimo, internacional; e/ou b) ter suas origens fortemente ligadas aos estilos primordiais de Okinawa (Naha-Te, Tomari-Te e Shuri-Te). Estabelecendo esse recorte, segundo o primeiro critério, permaneceram os quatro principais estilos filiados à WKF, à WUKF e à WUKO: Gōjūu-ryū, Shitō-ryū, Shōtōkan-ryūe Wadōryū. Cada um desses estilos e/ou escolas possuem símbolos próprios, os quais serão debatidos a seguir. É necessário ressaltar a importância dos estilos escolhidos para esse estudo, pois são os que possuem o maior número de praticantes espalhados pelo mundo ${ }^{15}$.

\section{Gōjū-ryū}

Estilo fundado oficialmente no ano de 1933, por Chōjun Miyagi ( ${ }^{*} 1888$ - †1953). A maior parte dos ensinamentos que Miyagi utilizou para construir o estilo Gōjū-ry $\bar{u}^{\mathrm{n}}$ foram ensinados a ele por Kanryō Higaonna $\left({ }^{*} 1853\right.$ - †1915), mestre fundador do Naha-Te ${ }^{25-26}$. O estilo é caracterizado pelo uso de técnicas retas aliadas a outras mais suaves e circulares, que visam trabalhar os aspectos sutis do ser humano (mente e espírito), devido à influência direta que o $\mathrm{Naha-Te}$, estilo que o fundamentou, exerce sobre ele ${ }^{27}$.

Trata-se de uma busca por equilíbrio entre os opostos, no sentido de se complementar ${ }^{28}$. Isso é

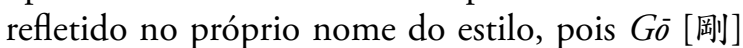
significa duro, rígido; $J \bar{u}$ [ 柔] é suave, flexível; e $R y \bar{u}$ [流] pode ser entendido como via ou estilo. Ou seja, "Via/Estilo do Rígido e do Flexível"25,29-31.

Tal filosofia é incorporada em um dos símbolos utilizados pelo estilo (FIGURA 1, esq.) ${ }^{\circ}$, o qual representa o Céu e a Terra, em japonês descritos como kenkon . O céu é representado na parte arredondada, expressando a suavidade, enquanto a terra é a parte reta, ou seja, a rigidez, harmonizando-se entre si e formando uma unidade na/da natureza. É importante salientar que o caractere dentro do emblema é o brasão da família Miyagi ${ }^{28}$. O símbolo utilizado pela escola Gōju-kai (FIGURA 1, centro), fundada por Gōgen Yamaguchi (*1909 - †1989), principal aluno de Miyagi, trata de três aspectos, que formariam uma pirâmide: Zen [全] (Mente), Ichi [-] (Um) e Ken [拳] (Punho), na qual a mente e o punho (que representa o Karate-Dō) são a base para a formação que leva ao topo do $\mathrm{Um}^{25}$. A mão fechada tem a concepção de firmeza e coesão obtida através desses três aspectos. Isso remete ao clássico ensinamento zen, "Ichi wa Zen, Zen wa Ichiq" ("Um é Todo, Todo é Um"), que exprime a ligação entre o meio e o indivíduo; a Totalidade (Zen) e o $\mathrm{Ser}^{32}$.

Há, também, o símbolo da escola Seigōkan (FIGURA 1, à direita), o qual exibe dois ramos de louro ao redor do nome escrito em ideogramas. Ao mesmo tempo em que representa algo da cultura de origem da prática (os kanji, ao centro), os significados utilizados aqui remetem à cultura desportiva da Grécia clássica, na qual os campeões eram agraciados com coroas de louro ou de oliveira, dependendo da cidade onde eram realizados os jogos. Isso denota uma aproximaçấo dos diferentes símbolos culturais, que pode ser explicado, talvez, pelo número cada vez maior de ocidentais que praticam Karate-Do. . Outro fator que necessita de atenção é que o a escola foi fundada em 1945 33 , ano em que teve fim a Segunda Guerra Mundial e o Japão passou a ser dominado politicamente pelos Estados Unidos, com inúmeros militares americanos tendo estabelecido moradia na região; o que pode ter influenciado essa aproximação cultural. 


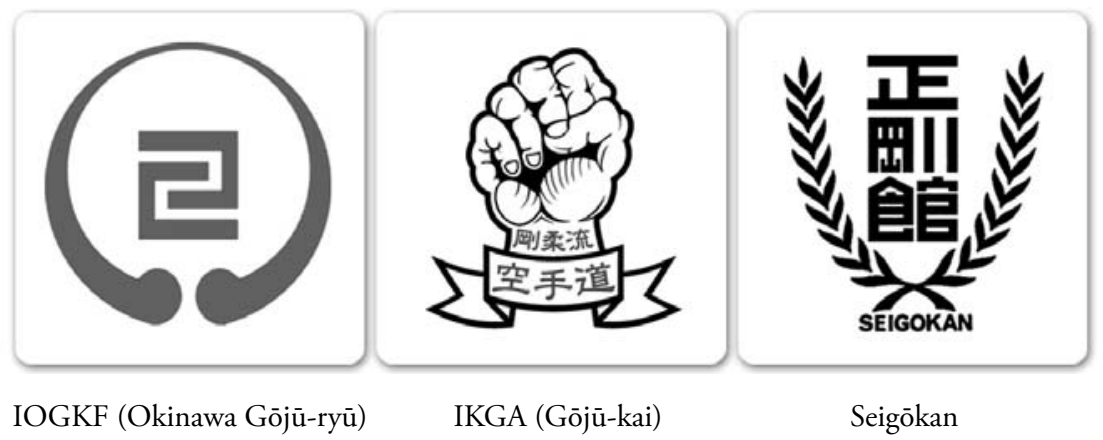

FIGURA 1 - Símbolos utilizados pelas escolas de Gōjū-ryūīn,34.

\section{Shitō-ryū}

Estilo criado em 1932 por Kenwa Mabuni (*1889 - †1952), que sintetizou diversas técnicas dos estilos primordiais de Okinawa. Graças a isso, Shitō-ryūr é um dos estilos mais extensos de Karate-Dō, com o maior repertório de técnicas dentre todos ${ }^{35}$. Ainda possui em seu repertório o treinamento de técnicas do Kobu-Dō de Okinawa, arte marcial que utiliza as armas originais dos camponeses dessa regiáo ${ }^{17}$.

O termo Shitō-ryū provém das iniciais dos nomes dos dois principais mestres de Mabuni, Ankō Itosu [安恒 系洲] (*1831 -†1915) eKanryō Higaonna [寛量東恩 納]: o ideograma 系 representa a sílaba "ITO" do nome "Itosu", podendo ser lido como "Shi"; o ideograma 東 representa a sílaba " $H I G A$ " do nome "Higaonna”, com pronúncia alternativa de " $T \vec{o}$ "; quando lidos dessa forma os caracteres adquirem a pronúncia "Shi" - $T \vec{o}$ ". Conforme já descrito anteriormente, o ideograma $r y \bar{u}$ [流] significa "via" ou "estilo". Embora sem uma tradução literal, Shitō-ryū pode ser interpretado como "Estilo dos Mestres Itosu e Higaonna"36.

O símbolo do estilo (FIGURA 2) é o escudo da família Mabuni ${ }^{15}$, emblema que representa a harmonia. As duas metades separadas (semelhantes às portas japonesas feitas de madeira e papel) remetem à ideia de duas pessoas que se encontram frente a frente, unidas na busca pela paz. Sua data de criação é desconhecida, mas acredita-se que existia há muitas geraçóes antes de ser adotado pelo fundador como parte do estilo ${ }^{37}$.

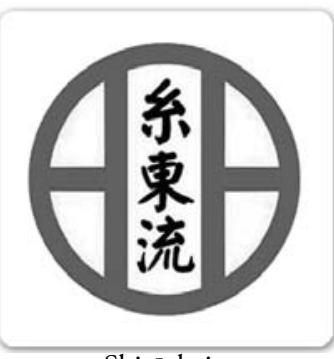

Shitō-kai

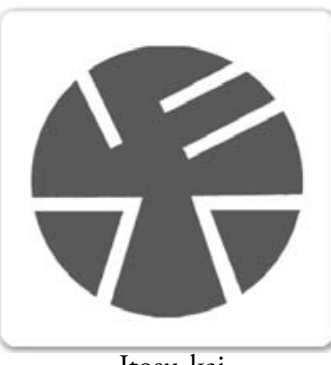

Itosu-kai

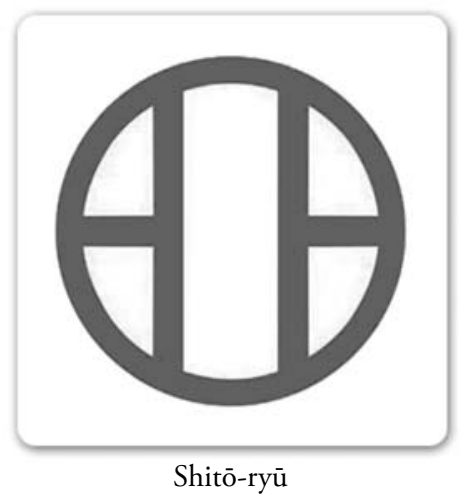

FIGURA 2 - Símbolo universal do estilo Shitō-ry $\bar{u}^{16,36}$.

Apesar de todas as linhagens desse estilo reconhecerem o símbolo de seu criador de forma geral, cada uma delas possui um brasão próprio (FIGURA 3). A Shitō-kai utiliza basicamente o brasão familiar com o nome do estilo ao centro, em kanji. A escola Itosu-kai faz utilização do caractere chinês "Ito" estilizado dentro de um círculo vermelho, que remete diretamente às cores da bandeira japonesa ${ }^{38}$. As linhas Inoue-Ha e Hayashi-Ha utilizam-se de formas gráficas mais simples, preenchidas meramente com o nome da escola e alguns grafismos. Aqui encontramos, novamente, um símbolo que contém uma coroa de louros, acompanhada de um punho fechado, muito comum em símbolos de Karate-Dō, representando a "mão" do nome da arte.

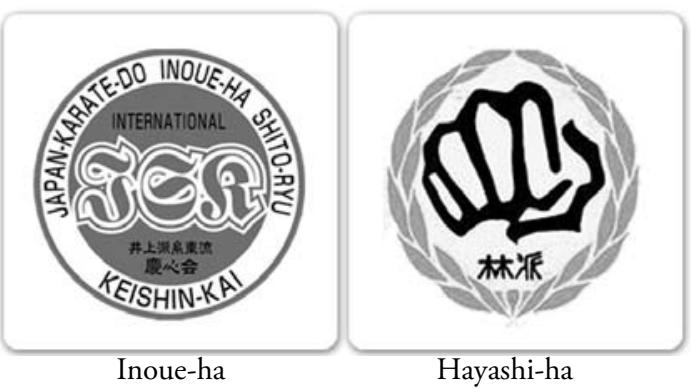

Fonte: arquivo pessoal do autor.

FIGURA 3 - Símbolos utilizados pelas escolas de Shitō-ryū. 


\section{Shōtōkan-ryū}

Estilo desenvolvido por Gichin Funakoshi $\left({ }^{*} 1868\right.$ - †1957), considerado o Pai do Karate-Dó moderno e um dos grandes difusores da arte no Japão. O repertório técnico do Shōtōkan-ryū é fundamentado principalmente no estilo Shuri-Te $e^{39-40}$.

Mestre Funakoshi não denominava, a princípio, seu estilo como Shōtōkan-ryüs, apenas afirmava que ensinava Karate-Dō, mesmo que a arte seguisse sua visão e entendimento particulares. Foram os membros do comitê nacional de patrocinadores de Karate, que em homenagem a ele, confeccionaram uma placa para seu local de treino com o nome Shōtökan, que passou a ser o nome do estilo desde entâo. "Shö" [松] significa pinheiro, enquanto “ $T \overrightarrow{0}$ " [涛] é entendido como o som que as árvores fazem quando o vento bate nelas. O caractere "Kan" [館] significa edificação, salão, ou até mesmo casa. Além disso, "Shōtō" era o pseudônimo que Funakoshi usava para assinar suas poesias quando jovem, pois sempre se recolhia em um lugar mais afastado para escrever, onde encontrasse inspiração ouvindo apenas o barulho dos galhos dos pinheiros ao vento. Portanto, apesar de não ter a tradução literal, Shōtōkan é entendido como "Casa de Shōtō" ${ }^{41}$.

O símbolo principal do estilo (FIGURA 4) é um tigre branco dentro de um círculo, o Tora no $M a k i^{\mathrm{t}}$, originalmente desenhado pelo artista japonês Hoan Kosugi $\left({ }^{*} 1881\right.$ - $\left.† 1964\right)$, e utilizado na capa do primeiro livro escrito por FUnAKOSH ${ }^{\mathrm{u}, 41}$. O tigre parece remeter a elementos da cultura chinesa, pois uma figura similar está presente entre as imagens dos animais guardiães no Taoísmo chinês, os quais foram assimilados pela cultura budista japonesa ${ }^{42}$. Possivelmente, Hoan teria se inspirado em uma escultura de alto-relevo chinesa, referente ao guardiáo do Oeste, que representa o arquétipo do guerreiro ${ }^{43}$. Além disso, a figura do tigre já esteve presente no discurso de Funakoshi em outros momentos: "o verdadeiro budōka é aquele cujo olhar faz um tigre encolher-se de medo e possui um sorriso que conquista até mesmo o coração das crianças" ${ }^{\prime 4}$.

Apesar de todas as escolas de Shōtōkan-ryū reconhecerem e utilizarem amplamente a figura do tigre, todas elas possuem seus próprios símbolos, cujos significados são diversos (FIGURA 5). A Japan Karate Federation (JKA) se utiliza de um emblema que remete claramente à bandeira da prefeitura de Okinawa (FIGURA 6), mas com tons mais avermelhados. Essa bandeira, em seu símbolo central, remete ao oceano (círculo maior), o elemento que identifica todo o arquipélago, à paz (circulo médio, de cor branca) e ao desenvolvimento e ao progresso (círculo menor, central) ${ }^{45}$. Apesar da clara homenagem ao local de origem da arte, de acordo com a própria associação ${ }^{46}$, seu Karate- $D \bar{o}$ é baseado nos princípios do Kokufü-Bunka Karate-Dōv, ou seja, uma arte marcial baseada na tradição japonesa e do Bushido ${ }^{\mathrm{w}}$, código de conduta dos antigos samurai. Essa escolha de entendimento e pedagogia parece remeter ao desenvolvimento que o antigo Töde teve ao ser inserido como prática cultural japonesa, tornando-se o atual Karate-D $\bar{o}$. Isso reforça o caráter multicultural do surgimento e evoluçáo dessa arte.

É importante salientar que esse desenvolvimento torna-se muito importante ao entendermos que o Karate- $D \bar{o}$ não era uma prática tipicamente japonesa, mas acaba sendo registrado como um Budō, a despeito disso. Essa característica adaptativa da arte, que evolui conforme a demanda cultural, remete às próprias ideias de Gichin Funakoshi, que via a necessidade do Karate-Dō em acompanhar as necessidades de cada época ${ }^{13}$.

A Japan Karate Shoto Federation (JKS) é outro exemplo de escola que utiliza a coroa de louros, aqui envolvendo um círculo dourado que representa o Sol; trata-se de uma alusão não táo clara ao conceito do Círculo de Sol (Hinomaru ${ }^{x}$ ) da bandeira japonesa. A Shotokan Karate-Do International Federation (SKIF) apenas colocou a figura do tigre dentro de um círculo vermelho, novamente uma referência às cores e elementos da bandeira japonesa. O símbolo que mais chama atenção, talvez por sua simplicidade, é o da Nihon Karate Shotokai (NKS): um círculo vazio com um triângulo o preenchendo, que por sua vez possui um ponto quadrado ao centro. Essa expressão minimalista reflete diretamente as características dessa escola, a qual busca apenas a prática do Karate-Dō como um fim, sem objetivos competitivos ou desportivos ${ }^{47}$. Seu grafismo está ligado a três conceitos da cosmogonia Shintō, representada por três símbolos (pirâmide, círculo e quadrado), os quais representariam o "mistério da vida": a pirâmide representa o Éter, uma energia primordial, que daria origem às formas fluidas representadas pelo círculo (líquidos, energias), que finalmente possibilita o surgimento de elementos sólidos (mundo material), representado pelo quadrado. Também representa a natureza, a força criadora que alimenta tudo; em outro significado representa o passado, o presente e o futuro ${ }^{48-50}$. 


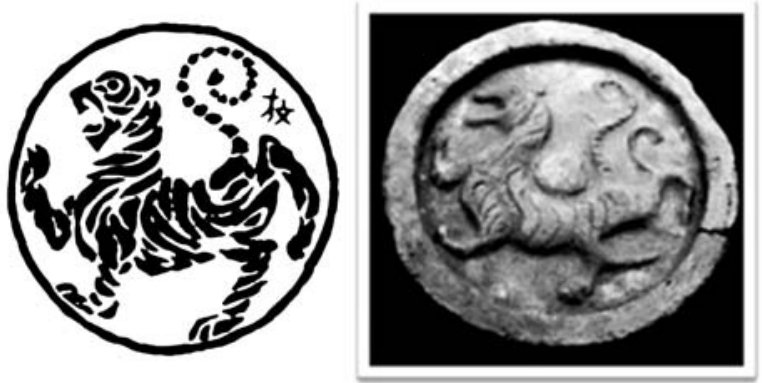

Fonte: Adaptado de http://karatescience. esporteblog.com ${ }^{43}$.

FIGURA 4 - A pintura de Hoan Kosugi, símbolo universal do Shōtōkan-ryū (esq.) e o relevo taoísta original que o teria inspirado (dir.).

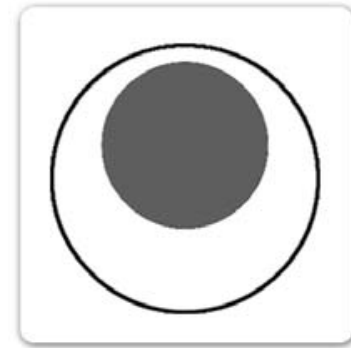

JKA

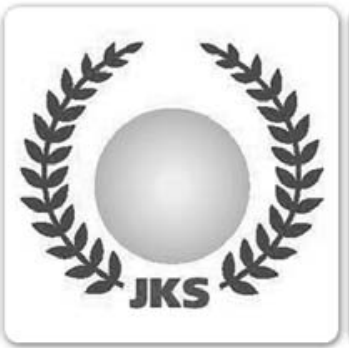

JKS

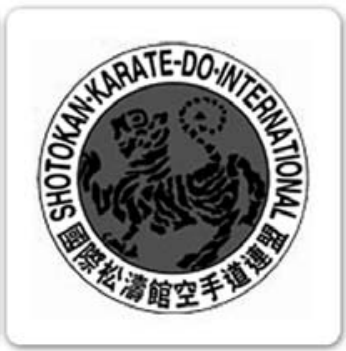

SKIF

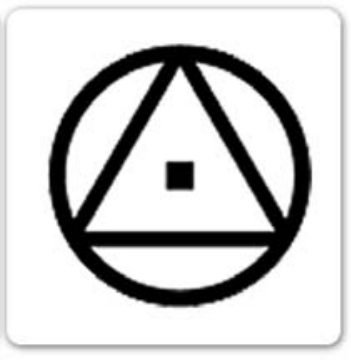

NKS

FIGURA 5 - Símbolos das escolas de Shōtōkan-ryū.

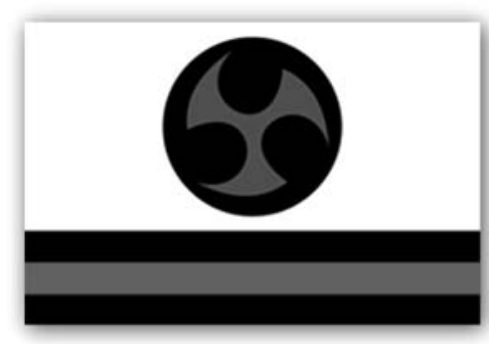

1869 a 1875

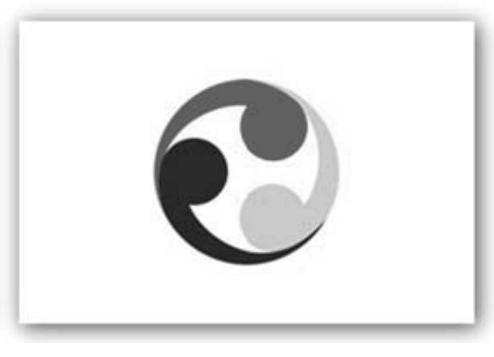

1875 a 1879

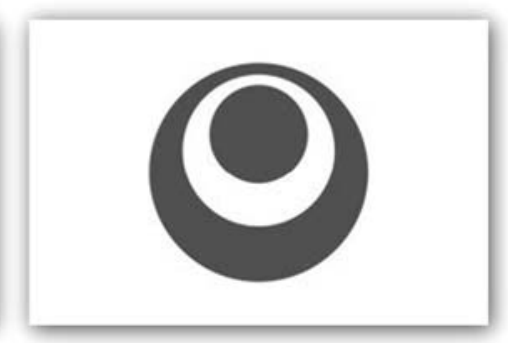

1879 em diante

FIGURA 6 - Bandeiras de Okinawa ao longo dos anos.

\section{Wadō-ryū}

Estilo criado pelo mestre japonês Hironori Ōtsuka $\left({ }^{*} 1892\right.$ - †1982) em 1932, sendo este o único desenvolvido no Japão dentre os chamados Quatro Grandes Estilos ${ }^{15,51}$. Atualmente existem três escolas principais do estilo, conhecidas como Wadō-ryü Renmeì , Wadō-ryū Kokusai ${ }^{2}$ e Wadō-ka $i^{\text {aa }}$, sem diferenças aparentes em suas filosofias, apenas na parte técnica e em seus órgáos dirigentes, mas ambos seguindo o modelo proposto por Ōtsuka em sua criação.

Esse estilo não possui um símbolo central como alguns outros, mas um elemento central: uma pomba. Para entender isso, é necessário compreender sua filosofia. O nome Wadō-ryū significa, em tradução literal, "Via/Estilo do Caminho da Harmonia", ideia central da doutrina ensinada por Hironori Ōtsuka. Em sua poesia ("Ten Chi Ji no Ri Dō Wasuru”, FIGURA 7), o mestre ensina que o caminho proposto nas artes marciais não deve ser apenas de técnica de luta, mas o caminho da paz e da harmonia.

Essa poesia é interpretada da seguinte forma (FIGURA 8): o primeiro e o último kanji juntos formam o termo "Wadö"; O kanji "Ten" significa céu, paraíso, ar; "Chi" é terra, solo, chão; "Jin" representa os homens, a humanidade e os seres humanos; " $R i$ $D \vec{o}$ " significa Caminho da Razão, da Verdade; e " $W a$ " significa a soma do todo, a Harmonia ${ }^{52-53}$. Assim, procura-se conectar os três conceitos sagrados (céu, terra e seres humanos), apresentados aqui como os
Fonte: arquivo pessoal do autor.

Fonte: arquivo pessoal do autor. 
círculos básicos e norteadores da prática. Esses três elementos fazem referência direta aos significados de um símbolo da religião Shinto ${ }^{\text {tb }}$, o Tomoe ${ }^{c \mathrm{cc}}$, ou mais precisamente o Mitsudomoe $\mathrm{d}^{\mathrm{d}, 48}$, que representa diversos aspectos filosóficos e espirituais de integralidade e movimento universal. Quando é apresentado com três pontas, trata da permanente relação entre Homem, Céu e Terra; ou seja, a relaçáo entre o ser humano, a natureza e o sagrado/divino ${ }^{49,54-55}$. O símbolo foi utilizado na própria bandeira de Okinawa em duas de suas versōes (FIGURA 6). Essas três esferas seriam circundadas por uma maior, a Razão, que se combina com os demais, naturalmente, para formar e ser englobada pela paz e harmonia, manifestada pela combinaçấo do todo ${ }^{52}$. Essa interpretação é apenas uma das muitas possíveis; se aprofundarmos o olhar, os significados encontrados serão muitos e cada vez mais elaborados, pois os kanji possuem ainda muitas outras interpretaçóes (luz, sol, chuva, colheita dos grãos, desejo, amor, etc.).

Podemos observar que a estrutura dos símbolos adotados também segue um padrão, o mesmo presente nos círculos da poesia (FIGURA 8), incorporando-a graficamente na forma de uma pomba branca (círculo maior) englobando um círculo menor (FIGURA 9). A pomba, aliás, é o elemento central de todas as escolas, evidenciando aqui o uso de um símbolo de paz atribuído ao cristianismo, mais precisamente à passagem bíblica referente ao dilúvio (Gênesis 8:11). É importante notarmos que o uso do pássaro, aqui, faz uma alusão a algo maior do que o conceito de paz, associando-o à harmonia (expressa no próprio nome do estilo): enquanto a paz pode estabelecer uma situação igualitária a todos, sua associação com a harmonia torna-a mais equânime, respeitando as diferenças entre os povos e indivíduos.

O elemento secundário dos símbolos, no entanto, varia entre as diferentes escolas: no caso da Wadōryū Renmei está o kanji Harmonia (Wa), a Wadō-kai expóe um punho estilizado e a Wadō-ryū Kokusai utiliza o círculo vermelho, talvez remetendo à bandeira do Japão. No entanto, pode-se perceber certa correspondência nas formas desses emblemas com o da bandeira atual de Okinawa, principalmente no da Wadō-ryū Kokusai (FIGURAS 6 e 9).
Fonte: http://www.wadoryu.jp/english.htm| ${ }^{52}$
Fonte: http://www.wado-ryu.jp/english.html'52; Prof. Tomoko Kimura Gaudioso.

\section{和天地人之理道 WAsuru TEN CHI JIN no RI DO}

FIGURA 7 - Poesia de Otsuka escrita nos ideogramas kanji.

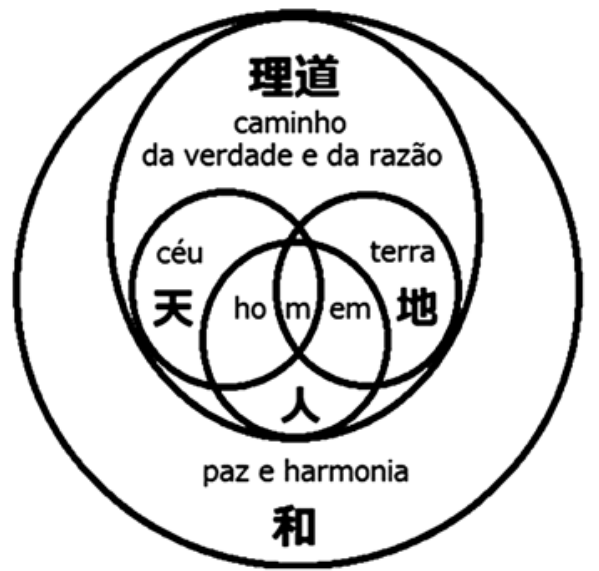

FIGURA 8 - Representação gráfica da filosofia da poesia de Otsuka. 


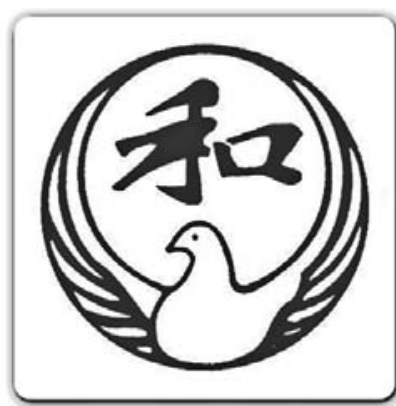

Wadō-ryū Renmei

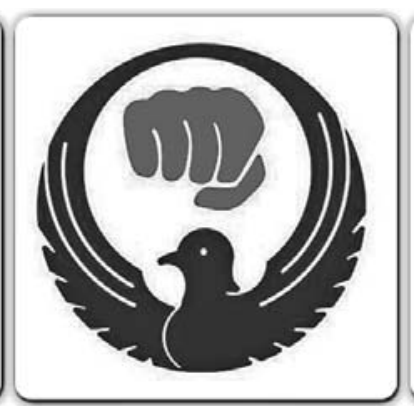

JKF Wadō-kai

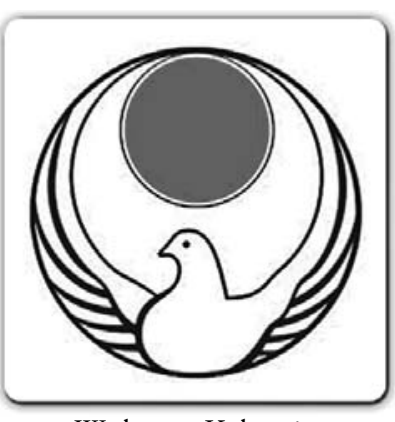

Wadō-ryū Kokusai
Fonte: arquivo pessoal do autor.

FIGURA 9 - Símbolos das escolas de Wadō-ryū.

\section{Diversos significados}

O estudo das simbologias presentes nos emblemas das escolas de Karate-Dō, objetivo desse estudo, torna-se importante para uma compreensão mais profunda dos diferentes conjuntos de valores presentes nessa prática. Cada escola, apesar de seguir um grupo de regras comum a todos os Budō, desenvolveu sua própria visão de mundo, utilizando seus símbolos para reforçar ou externar tais conceitos.

Grande parte dos símbolos analisados demonstra um aprofundamento cultural em seus grafismos, sendo alguns elementos até de aspecto espiritual ou religioso. Há incidência, também, de elementos mitológicos asiáticos: um dos animais sagrados da cultura chinesa, gravados em pedra, pôde ser encontrado em grande parte dos símbolos das escolas de Shötökan-ryū, bem como no próprio selo que define o estilo. Outros remetem a elementos mais sutis de caminhos religiosos, como o Homem, o Céu, a Terra, a Natureza e o Espírito, da religiáo Shintō. Apesar de, conhecidamente, o Karate-Dō não possuir, em sua origem, ligação direta com nenhuma prática religiosa, surge em um reino que, em sua própria bandeira, possuía um símbolo de evolução espiritual, do qual os conceitos são transportados para os emblemas de certas escolas. Além disso, o Karate-Dōé criado e desenvolvido por pessoas com crenças e valores comuns ao contexto de diversas religióes, atrelando elementos desse meio a sua filosofia. Tais fatos não podem ser ignorados. Esses simbolismos, em si, mostram um aspecto relevante para a compreensão do próprio fenômeno multicultural nomeado Karate-Dō, que surgiu e se desenvolveu como uma amálgama entre a cultura local de Okinawa, da China e do Japão.

Apesar de náo ter surgido em território japonês, o Karate-Dó foi transportado culturalmente para lá. E mais importante: a arte, em sua configuração atual, é fruto de um grande processo de desenvolvimento, cuja participação japonesa foi fundamental para torná-la o que é hoje. Isso fica claro em alguns símbolos analisados, os quais se utilizam de formas e cores próprias da bandeira japonesa. Há também aqueles que preferem remeter à cultura de Okinawa, local de nascimento da arte, e outros, ainda, que mesclam os conceitos de ambas as regiôes. Um elemento marcante para esse entendimento é o uso do Hinomaru (Disco de Sol) por várias escolas, seja de forma direta ou indireta, apontando o Karate-Dō como uma prática apropriada (ou em constante processo de apropriação) pelo povo japonês. A presença de brasōes familiares também se mostrou muito comum, como ocorre nos estilos Göjū-ryū e Shitō-ryū, os quais pertencem às famílias de seus fundadores.

Símbolos de maior significado no ocidente também estão presentes, como a pomba branca da paz, uma possível influência cristã, e a coroa de louros, da Grécia clássica. Esses são marcantes em escolas mais contemporâneas, como é o caso do estilo Wadō-ryū e algumas escolas de Shōtōkan-ryū. Isso ocorreu, possivelmente, graças ao estreitamento cultural entre os povos a partir do segundo terço do século XX d.C., decorrente, em parte, dos avanços sociais e tecnológicos. Devido a esse aspecto, o mundo torna-se cada vez mais diminuto, com informaçôes disponibilizadas de forma quase instantânea a uma grande parcela da populaçáo, aproximando culturas. Isso se reflete dentro do próprio Karate-Dō, que, enquanto uma prática cultural, faz parte de um processo constante e dinâmico de desenvolvimento.

Todos esses símbolos, mesmo separados, refletem a situaçáo atual do Karate-Dō no mundo, que náo se configura mais como uma arte de combate exclusiva para a sobrevivência, mas um modelo de desenvolvimento pessoal de múltiplas faces. Existem entidades que buscam a vitória em competiçôes desportivas, enquanto outras se recusam a participar desse sistema; tratam-se de formas diferentes de existir. No entanto, em nossa análise dos emblemas, nenhum estilo ou escola parece se apresentar 
como rival de outro em sua filosofia, mesmo que o sejam politicamente; são, sim, caminhos que se confundem e se completam.

Muitos estilos foram excluídos deste estudo por não atenderem aos critérios de inclusão supracitados ou, até mesmo, por não apresentarem o uso de emblemas próprios. Levando-se em conta que existem mais de 60 estilos de Karate-Dō catalogados, uma abordagem total seria impraticável nestas páginas e se configuraria como uma tarefa para toda a vida, pois novos estilos e instituiçóes surgem a cada dia. Entender e pesquisar tais conteúdos permite ao karateka $^{\text {ee }}$ ligar-se de novas formas a sua prática e ao Caminho escolhido, tornando a tarefa de catalogar e analisar os mais diversos símbolos do Karate-Dō essencial. O primeiro passo, no entanto, já foi dado.

\section{Notas}

a. Forma de escrita oriunda da China, que utiliza diversos caracteres para representar seus significados. É utilizada amplamente nos países orientais, sendo o Japão um deles.

b. Juntamente com Nippon e Kunrei, o Hepburn (Hebon-shiki Rōmaji) é um dos sistemas oficiais de romanização do idioma japonês, o Nihongo. O sistema Hepburn é o mais utilizado no Ocidente.

c. [平民]: Homem do povo, cidadão, plebeu. Palavra usada para designer os camponeses.

d. [親雲上]: Título de nobreza da classe militar guerreira no reino de Ryūkyū.

e. [唐手]: Mãos chinesas.

f. [島津氏]: Clã samurai proveniente de Kyūshū, sul do Japão, em meados de 1600 d.C.

g. [那覇], [首里], [泊]: Naha, Shuri e Tomari, respectivamente.

h. [那覇手]: Máo de Naha.

i. [首里手]: Mão de Shuri.

j. [泊手]: Mão de Tomari.

k. [武道]: Caminho da não-violência.

1. [大日本武德会]: Associação das Virtudes Marciais do Grande Japão.

m. [大四流]: Dai Yon Ryū.

n. [剛柔流]: Via/Estilo do Rígido e do Flexível.

o. Existe mais de um símbolo para o estilo na literatura, sendo adotado para esta pesquisa os mais citados nas referências escolhidas.

p. [乾坤]: Universo / Céu e Terra.

q. [一は全、全は一]: Um é Todo, Todo é Um.

r. [系東流]: Via/Estilo dos Mestres Itosu e Higaonna.

s. [松涛館流]: Via/Estilo da casa/salão de Shōtō.

t. [虎の巻]: Tigre no círculo.

u. A saber: Rentan Goshin Karate Jutsu [錬胆護身唐手術], ou Técnicas de Karate (Mãos Chinesas) para autodefesa.

v. [国風文化空手道]: Karate-Dō de cultura e costumes nacionais.

w. [武士道] Bushidō: Caminho do Guerreiro.

x. [曰の丸] Hinomaru: O Círculo do Sol; elemento que representa o Sol na bandeira japonesa.

y. [和道流連盟]: Federaçáo da Via/Estilo do Caminho da Harmonia.

z. [和道流国際]: Entidade Internacional da Via/Estilo do Caminho da Harmonia.

a. [和道会]: Escola do Caminho da Harmonia.

bb. [神道] Shintō: Caminho Divino; religião de origem japonesa.

cc. [鞆絵] Tomoe: Forma japonesa abstrata que se assemelha a um redemoinho.

dd. [みつどもえ] Mitsuedomoe: símbolo Shintō que representa o Céu, a Terra e o Homem.

ee. [空手家] Karateka: especialista em Karate. 


\section{Abstract}

\section{The symbols in the Karate-Dō styles}

The goal of this study is to interpret the different meanings in the emblems/symbols of the styles and schools of Karate-Dō, analyzing their internal elements and their importance within of this practice. This survey was composed by three distinct stages: 1) research and cataloging of the styles and schools of Karate-Dō with historical, cultural and political representation; 2) identification of the symbols used by each one of these styles and schools; and 3) analysis of each one of these symbols. This analysis is important for a deeper understanding of the different meanings involved in the practice of Karate-Dō. Although Karate-Dō follow a common set of values to all Budō, schools have their own worldview, using their symbols to reinforce or express such concepts. Some symbols which was analyzed demonstrates a cultural enrichment in their artwork, being recognized by some elements of religious or spiritual aspect. This symbolism, in itself, shows an important aspect to understand the multicultural phenomenon named Karate-Dō.

KEY WoRDS: Karate; Martial arts; Sport; Japanese culture; History.

\section{Referências}

1. Jung CJ. O homem e seus símbolos. 15a ed. Rio de Janeiro: Nova Fronteira; 2008.

2. Correia WR, Franchini E. Produção acadêmica em lutas, artes marciais e esportes de combate. Motriz. 2010;16:1-9.

3. Ross G. Japanese-English dictionary on-line [cited 2009 Abr 1]. Available from: http://nihongo.j-talk.com/parser/ search/index.php.

4. Bardin L. Análise de conteúdo. Lisboa: Ediçóes 70; 2000.

5. Rose G. Visual methodologies: an introduction to the interpretation of visual materials. London: Sage; 2007.

6. Frosi TO. Uma história do Karate-Do no Rio Grande do Sul: de arte marcial à prática esportiva [dissertação]. Porto Alegre (RS): Universidade Federal do Rio Grande do Sul; 2012.

7. Frosi TO, Mazo JZ. Repensando a história do karate contada no Brasil. Rev Bras Educ Fís Esporte. 2011;25:297-312.

8. Tan KSY. Constructing a martial tradition: rethinking a popular history of Karate-Dou. J Sport Soc Issues. 2004;28:169-92.

9. Nakazato J, Oshiro N, Miyagi T, et al. Okinawa Karate and martial arts with weaponry [cited 2005 Jun 20]. Available from: www.wonder-okinawa.jp/023/eng.

10. Ratti O, Westbrook A. Segredo dos samurais: as artes marciais do Japão feudal. São Paulo: Madras; 2006.

11. Shinzato Y, Bueno FA. Kobu-Do: as armas antigas de Okinawa. São Paulo: On-line; 2007.

12. McCarthy P, McCarthy, Y. Ancient Okinawan martial arts. Rutland: Tuttle; 1999. v.2.

13. Funakoshi G. Karatê-Do Nyumon: texto introdutório do mestre. São Paulo: Cultrix; 1999.

14. Yamashiro J. Okinawa: uma ponte para o mundo. São Paulo: Cultura; 1993.

15. Camps H, Cerezo S. Estudio técnico comparado de los Katas de Karate. Barcelona: Editorial Alas; 2005.

16. Stevens J. Três mestres do Budô: Kano, Funakoshi, Ueshiba. São Paulo: Cultrix; 2005.

17. Tazawa Y. História cultural do Japão: uma perspectiva. São Paulo: Ministério dos Negócios Estrangeiros; 1973.

18. DNBK. Dai Nippon Butoku-kai: concise history of Dai Nippon Butoku Kai [cited 2014 Fev 20]. Available from: http://www.dnbk.org/.

19. Gonella R. Do: viaggio attraverso il Karate alla ricerca dell'antico To-De. [S.l: s.n.]; 2003.

20. WKF. World Karate Federation. [homepage]. Madrid: WKF [cited 2008 Nov 26]. Available from: http://www.karateworld.org/.

21. WUKF. World Union of Karate-Do Federations. [homepage]. About WUKF [cited 2012 Nov 18]. Available from: http://www.wukf-karate.org/?pg=about.

22. WUKO. World United Karate Organization. [homepage]. About WUKO [cited 2012 Nov 18]. Available from: http:// www.wukf-karate.org/?pg=about.

23. Chambers J, Duff B, History Channel. Human weapon: karate. New York: AETN; 2008.1 DVD-Rom. 
24. Shinjyo K, Senaha S, Onaga Y. Three major schools of Okinawa Karate. Lake Forest: YOE; 2004. 2 DVD.

25. Urban P. The Karate Dojo: traditions and tales of a martial art. Rutland: Tuttle; 1991.

26. Toguchi S. Okinawan Goju-ryu: fundamentals of Shorei-kan Karate. Burbank: Ohara; 1976.

27. Higaonna M. Traditional Karatedo Okinawa Gōjū-ryū: performances of the Kata. Tokyo: Minamato Researchs; 1986. v.2.

28. IOGKF. International Okinawan Goju-ryu Karate-Do Federation [homepage]. Burlington: IOGKF [cited 2011 Dez 10]. Available from: http://www.iogkf.com/.

29. Reid H, Croucher M. O caminho do guerreiro: o paradoxo das artes marciais. São Paulo: Cultrix; 2004.

30. Michaelis. Dicionário prático de japonês-português. São Paulo: Melhoramentos; 2003.

31. Michaelis. Dicionário prático de português-japonês. São Paulo: Melhoramentos; 2001.

32. Kapleau P. Zen budismo: o caminho da iluminação. São Paulo: Arx; 2003.

33. SEIGOKAN. Goju-ryu Seigokan Karate-Do Kyokai [homepage]. Rio de Janeiro: SEIGOKAN; 2009. [cited 15 nov. 2013]. Available from: http://www.seigokan-sulamericana.com.br/gojuryu/.

34. APOGK. Associação Portuguesa de Okinawa Goju-ryu Karate-Do. 2009. Águas Santas: APOGK; 2009 [citado 10 dez. 2010]. Disponível em: http://www.apogk.pt/.

35. Aguiar J. Karatê Shito-ryu: os grandes mestres, os katas, entrevistas. São Paulo: Geográfica; 2008.

36. WSKF. World Shito-ryu Karate-Do Federation. Kaiso Kenwa Mabuni [homepage]. Hamasaki: WSKF; 2009 [cited 2011 Dez 10]. Available from: http://worldshitoryu.com/kenwamabuni.htm.

37. Seidenkai Brasil [homepage]. Porto Alegre: WordPress [citado 11 dez. 2011]. Disponível em: http://seidenkaibrasil. wordpress.com/shito-ryu/.

38. JKI. Japan Karatedo Itosu-Kai. About logotype. Tokyo: JKI; 2009 [cited 2013 Abr 7]. Available from: http://www. karatedo.co.jp/itosu-kai/english/e-logo/e-logo-ind.html.

39. Nakayama M. Karatê dinâmico. São Paulo: Cultrix; 2004.

40. Nakayama M. O melhor do karatê: fundamentos. São Paulo: Cultrix; 2000. v.2.

41. Funakoshi G. Karatê-Dō: meu modo de vida. São Paulo: Cultrix; 2000.

42. Schumacher M. Japanese Budhist statuary: gods, goddesses, shinto kami, creatures and demons. Schumacher; 1995. [cited 2010 Mar 29]. Available from: http://www.onmarkproductions.com/html/ssu-ling.shtml.

43. Frosi TO. O arquétipo do guerreiro e as conexôes transculturais com o taoismo chinês no Shotokan. 2010 [citado 3 dez. 2011]. Disponível em: http://karatescience.esporteblog.com.br/35844/O-Arquetipo-do-Guerreiro-e-as-conexoes-transculturais-com-o-taoismo-chines-no-Shotokan/.

44. Funakoshi G, Nakasone G. Os vinte princípios fundamentais do karatê: o legado espiritual do mestre. São Paulo: Cultrix; 2005.

45. OKINAWA. [homepage]. Símbolo da Província. Okinawa: OKINAWA. [citado 20 fev. 2014]. Disponível em: http:// www.okinawa.com.br/curiosidades/simbolo.html.

46. JKA. Japan Karate Association [homepage]. The world's foremost authority on Karate. Tokyo: JKA; 2009 [cited 2013 Abr 7]. Available from: http://www.jka.or.jp/english/e_index.html.

47. NKS. Nihon Karate-Do Shotokai [homepage]. Shotokai. Tokyo: NKS; 2003 [cited 2013 Abr 7]. Available from: http://www.shotokai.jp/english/index.html.

48. TUSM. Tradicional Uechi-ryu Shubukai Madrid [homepage]. Emblemas. Madrid: TUSM [citado 7 abr. 2013]. Disponible en: http://www.uechiryu-madrid.com/emblemas.html.

49. NIHON-BUNKA [homepage]. The Shinto Trinity. Yamaguchi: NIHON-BUNKA; 2012 [cited 2013 Abr 7]. Available from: http://www.nihonbunka.com/shinto/trinity.html.

50. Yamakage M. A essência do xintoísmo. São Paulo: Pensamento; 2010.

51. Buyo M. Karatê-Dô. São Paulo: Park Color; s/d. vol.1: fundamentos.

52. IFWKO. International Federation of Wado-ryu Karate-Do Organizations [homepage]. About Wado-Ryu. Okinawa: Wado-Ryu; 2011 [cited 2011 Dez 3]. Available from: http://www.wado-ryu.jp/english.html.

53. OWKRB. Organização Wado-Ryu Karate-Do Renmei do Brasil [homepage]. Títulos e condecoraçôes de Hironori Otsuka I. São Paulo: OWKRB; 2005 [citado 27 nov. 2011]. Disponível em: http://www.wadoryukaratedo.com.br/ br/historia.php.

54. AISF. Atsumi International Scholarship Foundation [homepage]. Japanese architeture and art net user systems: tomoemon. Tokyo: AISF; 2011 [cited 2013 Abr 7]. Available from: http://www.aisf.or.jp/ jaanus/deta/t/tomoemon.html.

55. JEL. Japan Emblem Library. Tomoe. Tokyo: JEL [cited 2013 Abr 7]. Available from: http://www.otomiya.com/kamon/ $\mathrm{kika} /$ tomoe.html.

406 • Rev Bras Educ Fís Esporte, (São Paulo) 2015 Jul-Set; 29(3):395-407 


\section{Agradecimentos}

Agradecimentos à professora Dr. ${ }^{a}$ Tomoko Kimura Gaudioso, do Instituto de Letras da UFRGS, por suas explicaçóes referentes às interpretaçôes dos kanji e símbolos do estilo Wadō-ryū utilizados neste artigo.

ENDEREÇO

Brandel José Pacheco Lopes Filho Escola de Educação Física Universidade Federal do Rio Grande do Sul

R. Felizardo, 750 90690-200 - Porto Alegre - RS - BRASIL e-mail: brandelfilho@gmail.com
Recebido para publicação: 14/06/2013

1a. Revisão: 30/11/2013

2a. Revisão: 27/02/2014

3a. Revisão: 13/o8/2014

Aceito: 20/10/2014 